\title{
STRENGTH AND DAMAGE ANALYSIS OF CONCRETE CONFINED BY STEEL CASING
}

\author{
Paulus IRAWAN* and Koichi MAEKAWA**
}

\begin{abstract}
The material-nonlinear 3-Dimensional finite element analyses were conducted for laterally reinforced concrete columns under axial compression. The elasto-plastic and fracture model served to investigate the confinement mechanism by steel casing. This paper points out two failure modes. One is that the whole lateral steel yields when the reinforced concrete (RC) section reaches the ultimate capacity. The other corresponds to the case where some part of lateral steel remains elastic at the ultimate condition of $\mathrm{RC}$ columns. The circular casing was found to exhibit the former mode of failure. On the other hand, the square casing was proved to come up with the latter mode of failure with greater deal of steel. In this case, the lateral stress arising in confined concrete was found not to be proportional to the amount of lateral steel.
\end{abstract}

Key Words : elasticity, plasticity, fracture, finite element, confined concrete

\section{INTRODUCTION}

From the practical view point, the role of lateral reinforcement has been investigated for improving the ductility and strength of reinforced concrete columns under axial compression. In general, design codes stated the minimum requirement of the amount of lateral reinforcement in order to reserve enough ductility of the member and to prevent the buckling of longitudinal reinforcement. But it is not quantified how the lateral steel could enhance the strength and ductility indicated by stress-strain relationships of confined structural concrete of arbitrary shapes and dimensions. It can be also said that the mechanism and the confinement efficiency by lateral steel has not been rationally deduced from a vast pool of experiments. Even if the same amount of steel would be placed as lateral confinement, the strength of reinforced concrete section in compression differs according to the shape of the section and the spatial arrangement.

There are plenty of design equations named "constitutive equations for confined concrete". Here, the efficiency dependent on the geometry of lateral steel is dealt with as an empirical shape factor $^{1,2), 4), 13,19)}$ or geometrically calculated effective sectional area ${ }^{6), 16)}$. This aspect has never been explained from microscopic view points of material inelasticity. Thus, many empirical stress-strain

* Graduate Student, Ms. Eng., Department of Civil Engineering, The University of Tokyo (7-3-1, Hongo, Bunkyo-ku, Tokyo 113, Japan).

** Member of JSCE, Dr.Eng., Associate Professor, Structural Division of Engineering Research Institute, The University of Tokyo (7-3-1, Hongo, Bunkyo-ku, Tokyo 113, Japan). relationships of confined concrete are not worthy of being named "versatile constitutive law", but regarded as design oriented empirical ones with fewer mechanical background. The confinement efficiency has to be theoretically explained as being rooted in the stress field and corresponding local inelasticity induced by the lateral steel indeed.

The objective of this research is to computationally investigate the effect of cross sectional shapes and arrangement of lateral steel on the strength and inelasticity of confined concrete. For this purpose, much technical attention is paid to the stress induced damage indicated by so called fracture parameter ${ }^{7)}$ as well as plasticity, which cannot be directly measured by tests. Firstly the authors deal with steel casing which represents the steel tubes or plates surrounding concrete. The densely arranged reinforcing bars (the spacing to referential dimension of section less than 0.1 ) along the axis of columns may be covered in the category of steel casing such as RC bridge piers with larger scale. Subsequently, the effect of spacing of lateral ties and spirals will be discussed based on the steel casing investigated here. The computer simulation was achieved by incorporating the elasto-plastic and fracture constitutive model with 3-dimensional finite element analysis. The analytical simulation and discussions are somewhat fundamental so that they could serve the future development of a rational design equation of confined reinforced concrete of axial compression.

\section{FINITE ELEMENT APPROACH}

The strength gain and ductility of confined concrete should not be treated as material properties but as macroscopic member characteristics. Then, the confinement which differs according to 
the way of arranging lateral ties has to be explained by the microscopic aspect such as non-uniform stress field developing over the volume and associated local inelasticity in each dimension and shape of members.

This paper tries to approach this mechanical aspect with the aid of the finite element analysis. In order to focus our discussion on the geometrical arrangement of lateral steel, the steel casing filled with concrete is selected as the extreme case where the spacing of lateral bars is zero. An enhanced constitutive model which can simulate the inelasticity of concrete mechanics is indispensable for analytical investigation. Here, the so called elastoplastic and fracture model ${ }^{8 \sim-10)}$ was adopted since the internal damage and plasticity arising in concrete under three dimensional stress states are quantified. The spacing of discretely arranged reinforcing bars will be discussed later as one of important factors after clarifying the confinement efficiency related to the shape of section and steel arrangement.

(1) Full 3-Dimensional Elasto-Plastic and Fracture Model

The nonlinear behavior of concrete is indicated by the plasticity, which denotes the residual deformation, and the internal damage, which represents the loss of the elastic shear stiffness induced by the occurrence of micro-defects and the internal stress intensity. Micro-defects were found not to affect the volumetric elastic energy capacity of concrete but the elastic energy capacity in shear mode ${ }^{8}$. Maekawa et al. introduced the fracture parameter $K$ to indicate the continuum damage occurring in shear elasticity of concrete, and proposed the second invariant of elastic strains $J_{2 e}$ as the primary indicator of internal stress intensity which evolves the continuum damage associated with the assembly of micro-defects. The damaging is formulated being suppressed by the 3-dimensional confinement denoted by $I_{1 e}$ as well ${ }^{8)}$. Thus, we have the following indicators of concrete nonlinearity as $^{10)}$,

Indicator of fracturing damage

$$
K=\frac{J_{2}}{2 G_{0} J_{2 e}}
$$

Indicator of plasticity

$J_{2 p}=\int \frac{\partial J_{2 e}}{\partial \varepsilon_{e i j}} d \varepsilon_{p i j}$

Indicator of internal shear stress

$J_{2 e}=\sqrt{\frac{1}{2} e_{e i j} e_{e i j}}$

Indicator of internal confinement

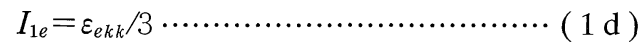

Indicator of total shear stress

$J_{2}=\sqrt{\frac{1}{2} s_{i j} s_{i j}}$

The fracture parameter $K$ represents the continuum damage of concrete in terms of elastic shear strain energy ${ }^{8}$. The smaller the fracture parameter $K$ is, the smaller capacity to absorb and release the elastic shear strain energy is achieved owing to the induced micro-defects. The plastic indicator $J_{2 p}$ is considered to represent the induced permanent deformation in shear mode and the isotropic plastic indicator $I_{1 p}\left(=\varepsilon_{p k k} / 3\right)$ is formulated as the inelastic dilatancy $^{8)}$. The shear elastic intensity $J_{2 e}$ represents the internal stress applied to effective non-damaged volume of concrete ${ }^{8)}$. The value of $K$ and $J_{2 e}$ are related to the strength gain of confined columns and $J_{2 p}$ to the ductility. In this paper, our concern is mainly oriented to the strength gain. The constitutive laws were proposed incorporating the above mentioned nonlinear indicators. The detail is discussed in references ${ }^{8) \sim 10}$. The constitutive equations concerned were installed in program COM 3 in COncrete Model series (COM 2), ${ }^{7} \mathrm{WCOMR}^{11)}$, $\left.\mathrm{WCOMD}^{17}\right)$.

\section{(2) Finite Element Model}

Two types of elements were used in the finite element model. Three-dimensional solid isoparametric element and modified three-dimensional plate element were adopted for representing concrete and steel casing respectively. The modified plate elements for steel casing were designed so that they carry only in-plane lateral membrane stress. Since the steel casing is not expected to resist any axial load and is also used to model densely arranged reinforcing bars, the modified plate element is idealized as perfect lateral agent of 1-dimensional stress without any stiffness in the longitudinal action. The contribution of out-ofplane flexural stiffness which is quite significant for heavily lateral reinforced concrete is neglected in purpose to model the so called "corner confined" concrete. In this concrete, the confinement is mainly introduced through the corner action. Thus, only the effect of axial stiffness of lateral steel, which dominates the behavior of lightly lateral reinforced concrete is considered. The discussion about the coupled effect of axial stiffness and outof-plane flexural stiffness will be presented in the next stage of this research.

Symmetry was taken into consideration in the discretization of the finite element model as shown in Fig.1. One-fourth of the section was represented by finite elements in the lateral direction. One isoparametric element consisting of 20 nodes was used to represent concrete for circular section. 

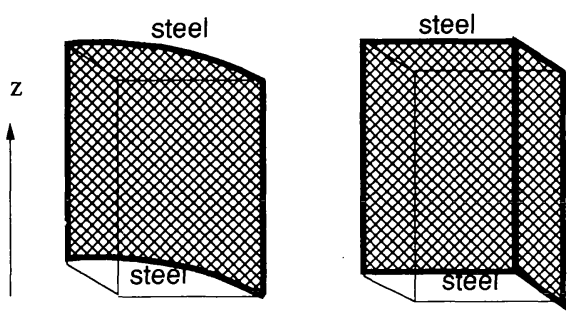

Steel Encased Columns
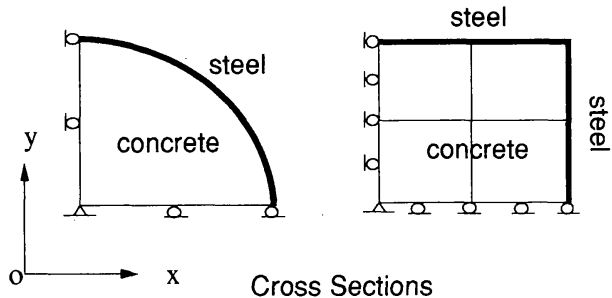

Cross Sections

Fig.1 Discretization of $1 / 4$ Model

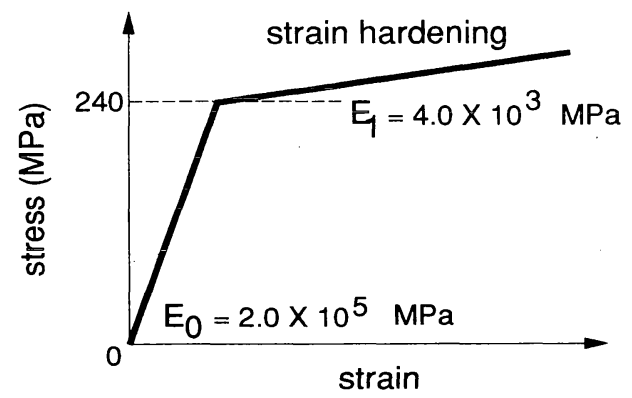

Fig.2 Elasto-Plastic Hardening Model for Steel Casing (Standard)

Although one element is enough to represent uniform field of stress as in the case of circular section, several elements are needed for the square one since the local stress is not uniform. Thus four elements were used to obtain more information of the fracture parameter of local points, internal stresses and strains around the square section. In the longitudinal direction, no division of element was assigned for concrete and steel. Second order of Gaussian integration was used in analyzing the model. Fig.1 shows the sectional and longitudinal discretization of the model. The elasto-plastic hardening model for steel casing is shown in Fig.2 with the standard material properties used in the analysis. The strain hardening is modelled to avoid the numerical instability and divergence of the iterative solution.

The loading was applied in $Z$ direction (See Fig.1) as an axial enforced displacement at the top surface of the concrete with the fixed boundary condition at the bottom surface. Since the steel plate elements do not have the capability to resist the axial load as stated before, the load will only be carried by the concrete, and the steel elements will produce the confinement action transferred to concrete through corners as the concrete expands. As the steel element does not take into account the bending of the steel casing, this analysis is thought to simulate the infinitely thin steel encasing or densely arranged lateral bars with smaller diameter.

The constitutive model for concrete used in this analysis ${ }^{10}$ is applicable to the non-localized fracture where the defects in concrete can be assumed as dispersed uniformly. Although the descending branch of mean stress-strain relation of members is obtained in this research (See Fig.3), the authors accepted results only up to the ultimate capacity as being reliable and independent on the finite element discretization. For analyzing softening behaviors in compression, the localized deformation has to be consistently predicted with the view points of fracture mechanics and/or interaction field of micro-defects ${ }^{12}$.

\section{CONFINEMENT INDEX}

The strength of concrete columns relies on the axial concrete stress at each location of member section. It can be said that the member axial strength with lateral confinement is the spatial averaged stress of confined concrete over the whole domain of a critical section. As for circular section, the local stress over a section can be assumed to be uniform due to its axial symmetry. But, for square section, we have non-uniform stresses appearing over a section. This is the reason why we need the finite element analysis in evaluating the cross section based strength and ductility of confined columns. At each Gauss integral point, the constitutive equations are applied.

The confinement efficiency by lateral steel depends on the amount of steel, strength of the constituent materials, and the shape of the section. In order to study the effect of sectional shape on the strength of confined concrete, the other influencing parameters should be kept constant. It is important to purely extract the shape dependent influence for the sake of further investigation on the effect of spacing of lateral ties. Here, the authors introduce the confinement index $\bar{\sigma}_{c}$ as,

$$
\begin{aligned}
& \bar{\sigma}_{c}=\frac{1}{V_{c}} \int_{V_{c}} \sigma_{c}(X, Y, Z) d V \\
& \sigma_{c} \equiv \frac{\sigma_{c, x x+} \sigma_{c, y y}}{2}
\end{aligned}
$$

where $\sigma_{c, i j}$ is defined as concrete stress tensor of two dimension [ij] and $V_{c}$ is the domain of 
concrete. The value of $\bar{\sigma}_{c}$ represents the spatial averaged lateral confinement stress over a whole volume of concrete.

Since the continuous steel casing is discussed, $\sigma_{c}$ is not dependent on coordinate $Z$ along the axis of members. Then, we have,

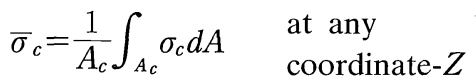

where $A_{c}$ denotes the cross-sectional area of concrete confined by the lateral steel.

According to the equilibrium condition of lateral concrete stress with lateral uniaxial steel stress $\sigma_{s}$, we have (See Appendix),

$$
\bar{\sigma}_{c}=-\frac{1}{2 V_{c}} \int_{V_{s}} \sigma_{s} d V
$$

where $V_{s}$ is the whole volume of laterally arranged steel.

The negative sign in equations represents compression, while tension is represented by positive. When the lateral steel would come up to the yield strength of steel used as $f_{y}$ over the whole volume of steel, according to Appendix, Eq.(4) is equal to,

$$
\bar{\sigma}_{c}=-\frac{1}{2} \rho_{s} f_{y} \text {. }
$$

where $\rho_{s}$ is the volume ratio of steel.

The value of $\rho_{s} f_{y}$ has been often used as a parameter to exhibit the amount of confinement in design equations proposed by Sargin ${ }^{13)}$, Sheikh and Uzumeri $^{16)}$, Mander et al. ${ }^{6}$, etc.

The value of $\rho_{s} f_{y} / 2$ has a clear physical meaning to represent the level of confinement if steel would reach the full plastic yield condition at the ultimate of the columns. But, provided that the elastic zone would remain in steel, $\rho_{s} f_{y} / 2$ might lose its mechanical background. The authors would like to insist that the sectional shape factor on the confinement efficiency should be discussed under the same magnitude of lateral confinement indicated by Eq. (2), not by $\rho_{s} f_{y} / 2$. The finite element approach enables us to computationally quantify the mean confinement index $\bar{\sigma}_{c}$ directly and rationally. This is the advantage of the microscopic approach to the macroscopic aspects of structural concrete.

\section{CONFINEMENT EFFICIENCY -ARRANGEMENT OF STEEL-}

The effect of the cross sectional shape is first discussed. In this section, the circular and square casings are concerned. The strength of confined concrete, which is equated with the axial capacity per unit area, is quantified by the absolute strength gain, not the normalized value by the uniaxial
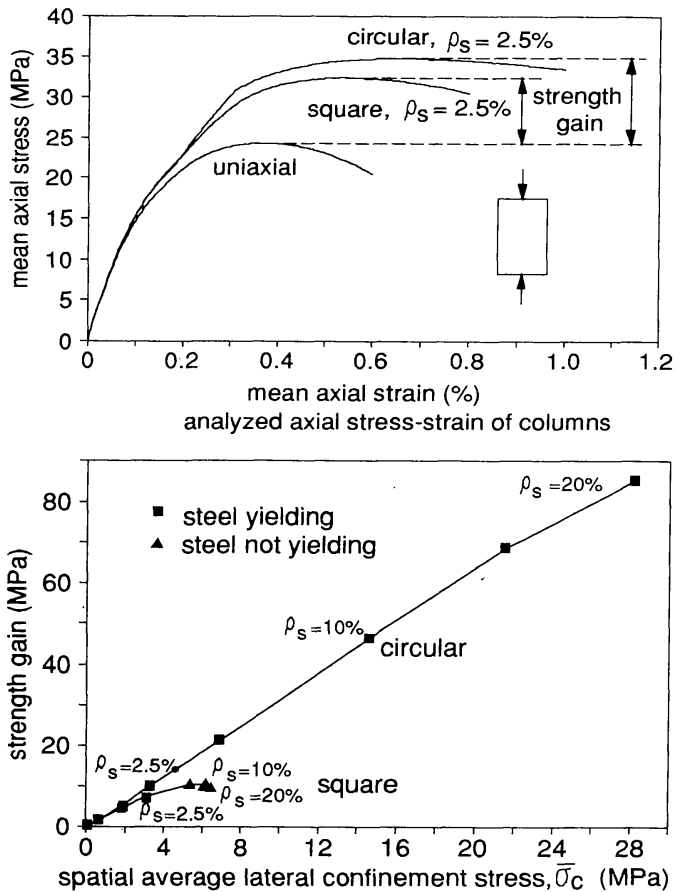

Fig.3 Computed Strength Gain and Laterally Induced Stress of Confined Columns

compressive strength. This approach has been experimentally and analytically verified and adopted for design equations proposed by others ${ }^{1) ~ 3)}$. It is because the lateral stress level which enhances axial strength is also associated with the uniaxial strength, and the sensitivity of the uniaxial strength to both the strength gain and corresponding lateral stress is nearly the same. The computed strength gain of the confined columns of circular and square sections is shown in Fig.3.

The yield strength of steel $f_{y}$ is $240 \mathrm{MPa}$ with the modulus of elasticity before yielding $E_{0}$ of 200,000 $\mathrm{MPa}$ and after yielding $E_{1}$ is $4,000 \mathrm{MPa}$ (See Fig.2). The concrete uniaxial strength $f_{c}^{\prime}$ is $25 \mathrm{MPa}$ and the modulus of elasticity is $20,000 \mathrm{MPa}$. The volume ratio of steel " $\rho_{s}$ " was controlled by changing the thickness of the casing. After this section, the compression is denoted positive unless any special note would be mentioned.

Let us compare the sectional shape dependency on the strength gain. Fig.3 shows that for the same lateral mean confinement $\bar{\sigma}_{c}$, which was evaluated by numerical integral in analysis, the strength gain of the circular section based on $f_{c}^{\prime}$ coincides with that of square one for the small spatial averaged lateral confinement. The level of stresses and confinement at each location around the square section is still almost the same, but as $\bar{\sigma}_{c}$ increases, the strength gain of the circular section is gradually 

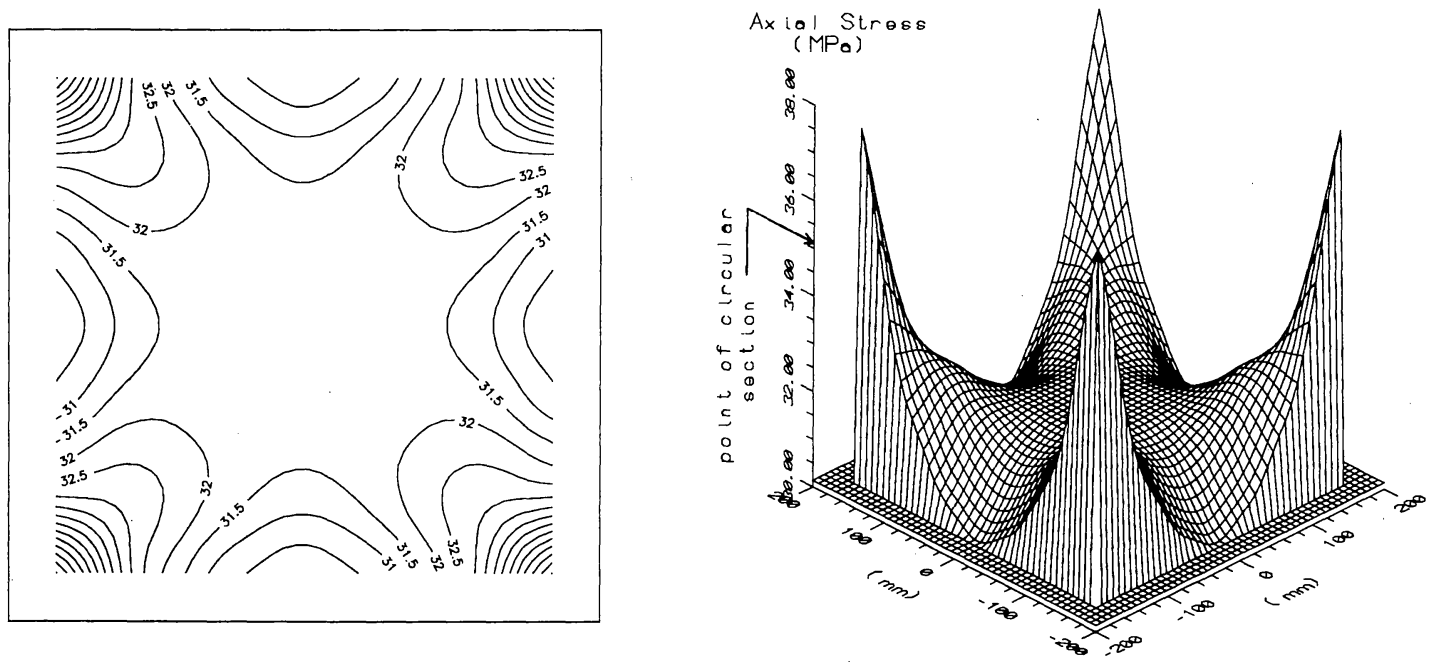

Fig.4 Distribution of Axial Stress, $\sigma_{c, z z}$ (Compression positive)
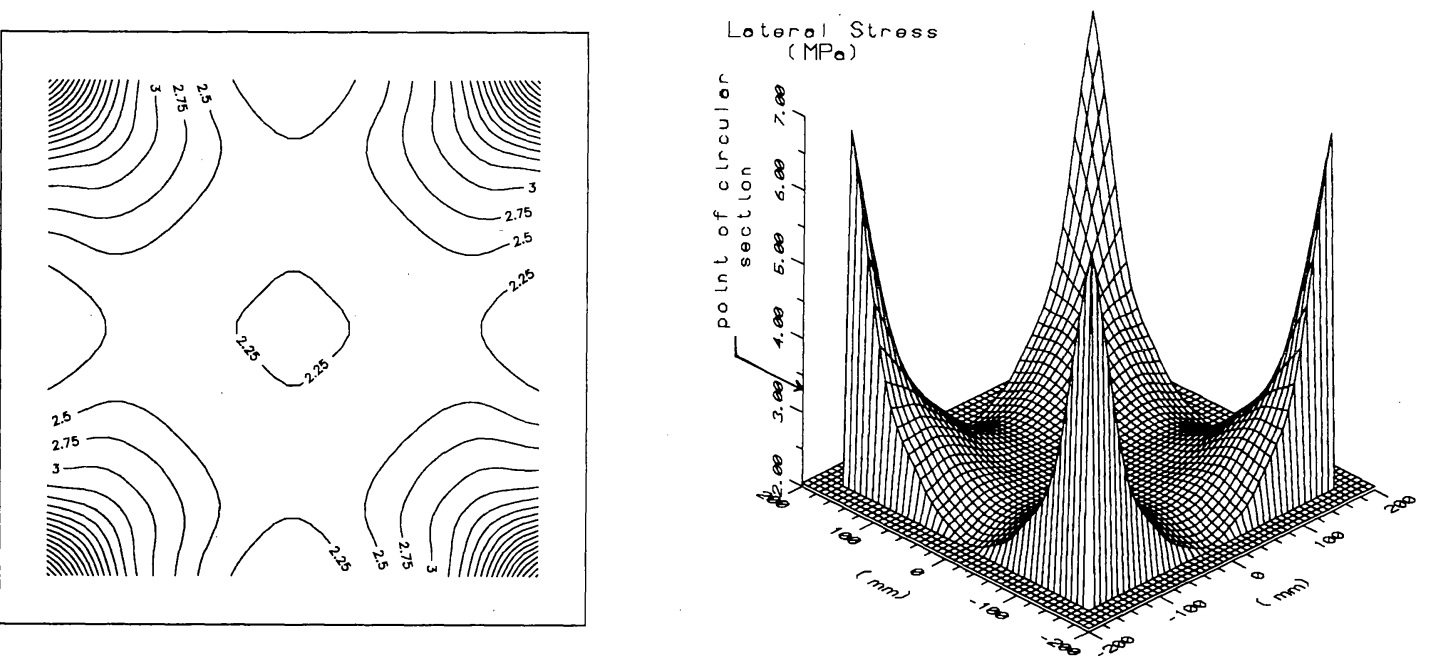

Fig.5 Distribution of Lateral Stress, $\sigma_{c}$ (Compression positive)
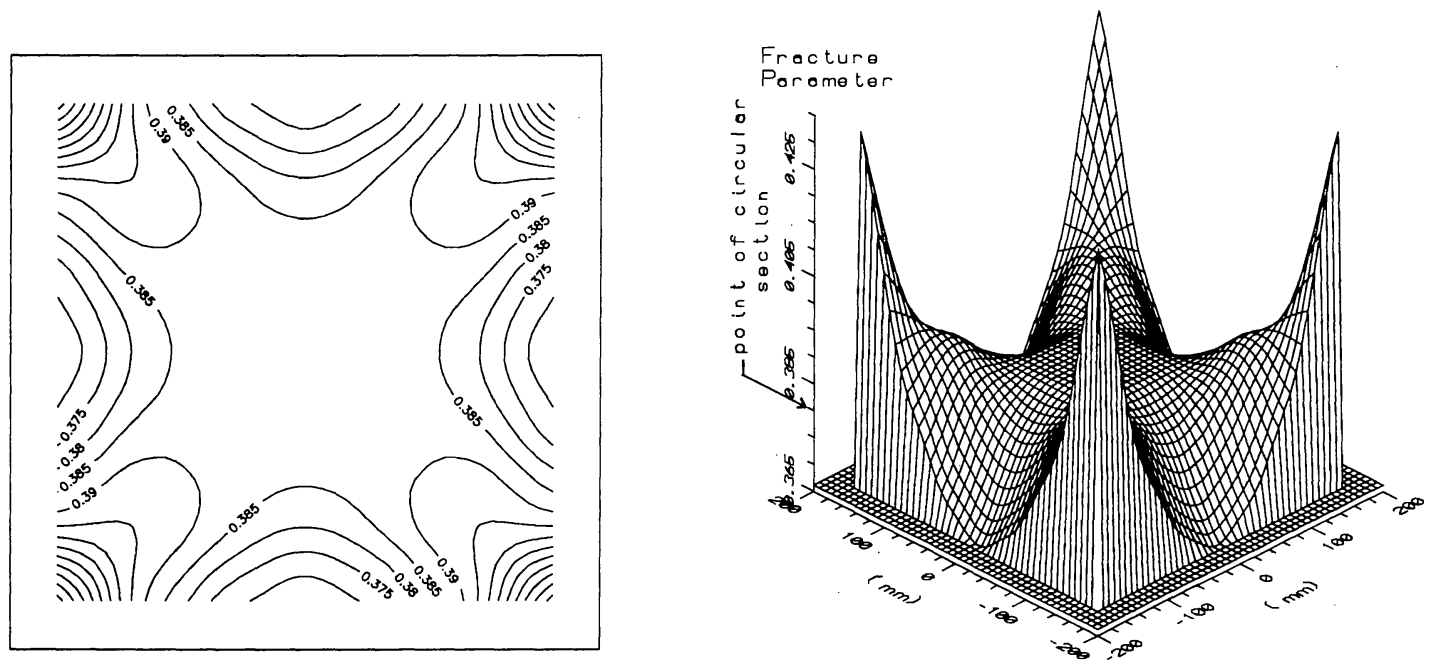

Fig.6 Contour Line of Fracture Parameter $K$ 
greater than that of the square one until the peak when the confined concrete loses the capability to induce plasticity in steel in square sections. Roughly speaking, the strength gain appears to be proportional to the mean confinement $\bar{\sigma}_{c}$ defined by Eq.(2) for both circular and square sections if the steel gets yielded. However, the sensitivity is different according to the geometrical placing of lateral steel. The lateral steel does not reach the yield when the larger volumetric ratio is allocated in square sections (See Fig.3). In this case, the spatial averaged lateral confinement stress of confined concrete is almost constant and the strength gain is also almost constant.

The lateral stress distribution in concrete is crucial and it results in the shape dependency. The distribution of axial and lateral local confinement stresses $\left(\sigma_{c, z z}\right.$ and $\left.\sigma_{c}\right)$ over the square shaped concrete are shown in Fig.4 and Fig.5. As the circular section creates perfect uniformity of stress, the values of axial and lateral stresses of circular sectional concrete having the same amount of lateral steel are shown for comparison in the same figures. The whole lateral steel yields and the same axial mean strain of members is realized. The stress field developing in the square section looks complex. The spatial averaging of the local axial stress in Fig.4 is equal to the "strength of confined structural concrete" at the ultimate condition. The sectional average of local lateral stresses for both square and circular sections (See Fig.5) balances with the common value of $\rho_{s} f_{y} / 2$ according to Eq.(3) and Eq.(5).

Around four corners (See Fig.4 and Fig.5), induced are higher lateral stresses which may cause higher axial local stresses being carried by concrete. The concrete at the intermediate zone between corners has less contribution to the axial load-carrying capacity, owing to the lower local confinement in the lateral direction. Around the central zone far from the corners, isotropic confinement is attained.

Compared with the uniform stress state in circular section, some portion in the square section has higher confinement and greater axial stresses and others smaller. Now, it can be said that the average of those local stresses exhibits lower performance on confinement compared with the circular section as a whole. For deeper understanding, the spatial distribution of the fracture parameter as a damage indicator of concrete is useful to enlighten the confinement mechanism. The contour line of the fracture parameter and its magnitudes in both circular and square sections are shown in Fig.6. At the four corners of the square section, the greater value of $K$ is seen, and at the

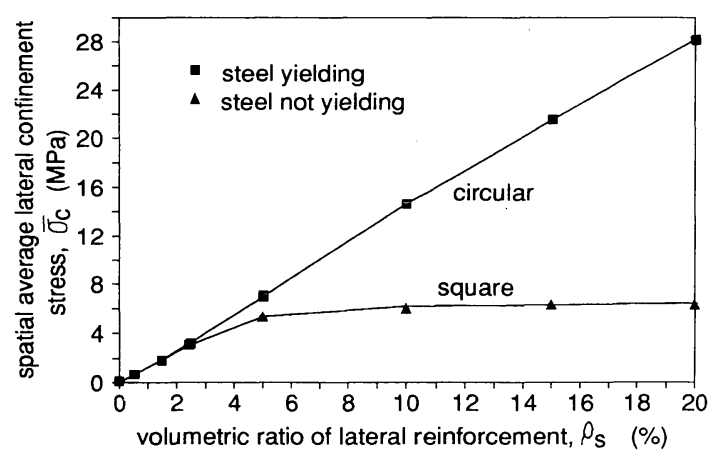

Fig.7 Effect of Amount of Steel to Mean Confinement

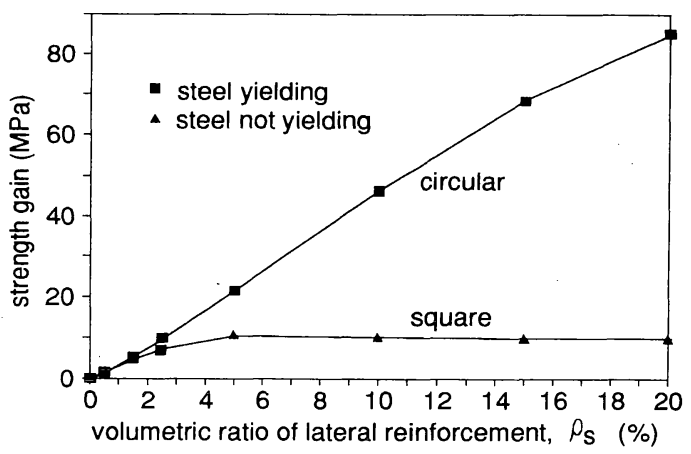

Fig.8 Effect of Amount of Steel to Strength Gain

middle points between corners, the smallest value is found. It means that much damage is concentrated on the concrete close to the steel casing but far from the corners of square section. Mechanically, the confinement state at the center holds the further progress of fracturing.

\section{CONFINEMENT EFFICIENCY - AMOUNT OF STEEL-}

To study the confinement efficiency of the concrete, the amount of steel was changed as a parameter. As far as the mechanical aspects are concerned, the material parameters specified in the previous chapter remained unchanged. The relationship between the amount of steel " $\rho_{s}$ " and the induced mean confinement $\bar{\sigma}_{c}$ over a section is shown in Fig.7. Also, the relationship of the strength gain versus the amount of steel is obtained as shown in Fig.8, incorporating Fig.7 and Fig.3.

Through these figures, it can be found that the non-uniformity in the stress distribution and confinement action in the square section induces two conditions of steel when the confined concrete reached the ultimate strength. One is that the whole steel is in plasticity, and the other is that the steel is still in the elastic zone. It should be also mentioned that the latter condition at the ultimate never come up to the circular section. For the small 


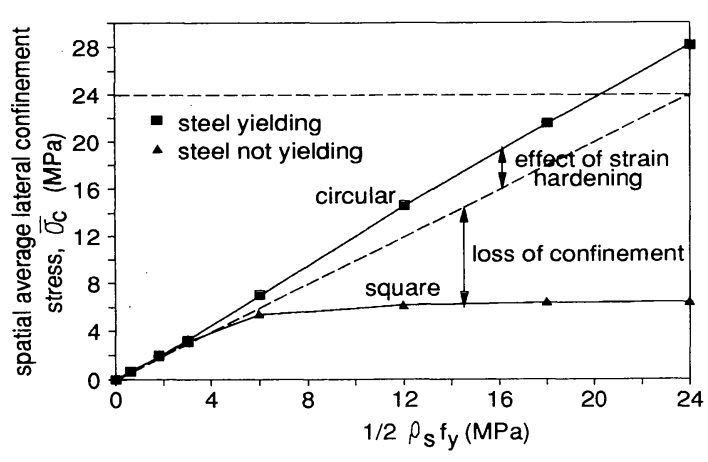

Fig.9 Relationship between Averaged Lateral Confinement Stress and $\rho_{s} f_{y} / 2$

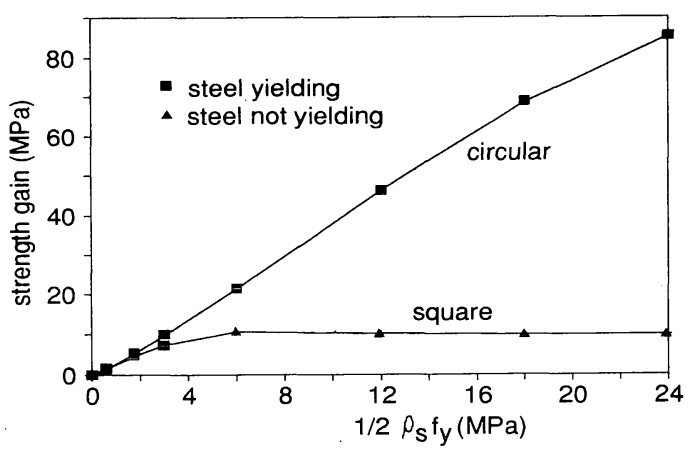

Fig.10 Sensitivity of $\rho_{s} f_{y} / 2$ to Strength Gain

amount of the steel, the first condition occurs to the square case, where the steel will yield when the confined concrete reaches the peak.

However, when the amount of the steel is increased, there is a condition that the steel is still in elastic zone even when the peak stress of concrete is reached as shown in Fig.7. The magnitude of the lateral stress becomes smaller than $\rho_{s} f_{y} / 2$ in Eq.(5) as shown in Fig.9 and the slight increase in the induced lateral stress level is observed even though larger amount of the steel would be added.

This is because the larger amount of steel gives rise to the higher concrete stress around the corner, but at the same time, much internal damage at the mid-points between corners as shown in Figs. 4 to 6. These weak points with inefficient local confinement may initiate the overall failure of confined structural concrete even though other portion would be strongly confined. Thus, confined squareshaped concrete loses the ability to ignite the plasticity to steel before failure of concrete itself. On the contrary, the uniformity of the stress distribution in circular sections produces relatively no weak point in any section. Uniform expansion of the confined concrete is always counteracted by the confinement action by the steel encasing until it would lose its stiffness after yielding. As a result, there exists the nonlinear sensitivity of the value of $\rho_{s} f_{y} / 2$ to the strength gain as shown in Fig.10 as far as the square cross section is concerned.

It is clear that the conventional parameter $\rho_{s} f_{y}$ which has been used in design equations loses its mechanical meaning when larger amount of steel would be placed in the case of square shape. Accordingly, the sensitivity of the steel volume to the confinement efficiency appears to be complex for square arrangement of steel. Sheikh and Uzumeri $^{16)}$ empirically adopted the square root of the volume ratio of steel in the design equation proposal. The square root sensitivity of the steel ratio is supposed to correspond to the nonlinearity appearing in Fig.7.

On the other hand, the strength gain of circular columns seems to be directly proportional to the amount of steel since the perfect proportion between $\bar{\sigma}_{c}$ and amount of steel is certified. So far, some design equations for square sections are based on the linear sensitivity of the volume ratio of steel to the confinement efficiency of the circular section $^{13), 19}$.

\section{CONFINEMENT EFFICIENCY -MATERIAL PROPERTIES-}

In order to study the sensitivity of the material properties of concrete and steel casing to the confinement, it is necessary to change one material property at a time. Three cases were studied for this purpose. The concrete compressive strength of $25 \mathrm{MPa}$ was used in case 1 and 3, while case 2 uses the compressive strength of $100 \mathrm{MPa}$. Case 1 and case 2 use the same yield strength of steel as 240 $\mathrm{MPa}$, but case 3 uses the yield strength of $960 \mathrm{MPa}$. By comparing case 1 with case 2, the effect of compressive strength of concrete to the strength gain and level of confinement can be studied. Case 1 and case 3 can be used to study how the yield strength of steel casing influences the strength gain and the confinement stress.

The strength gain was calculated based on the peak capacity of the confined concrete. As the plastic plateau of steel is not idealized for the requirement of stability of computation (See Fig.2), the capacity may keep on increasing owing to assumed strain-hardening of steel casing especially for some circular sections. In this case, the strength gain was defined as the capacity at the point where its strain reaches the actual hardening strain (ten times the yield strain) of the steel casing.

\section{(1) Strength of concrete}

The relationship of the strength gain versus amount of steel for both circular and square sections are shown in Fig.11 (Case 1 and Case 2). 


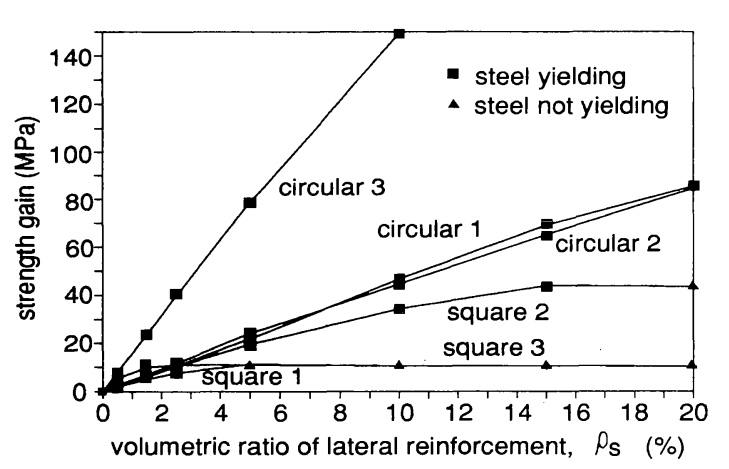

Case $1: f_{c}{ }^{\prime}=25 \mathrm{MPa}, f_{y}=240 \mathrm{MPa}$

Case $2: f_{c}^{\prime}=100 \mathrm{MPa}, f_{y}=240 \mathrm{MPa}$

Case $3: f_{c}^{\prime}=25 \mathrm{MPa}, f_{y}=960 \mathrm{MPa}$

Fig.11 Effect of Material Properties to Strength Gain

In case of the circular sections, where the concrete always has the capability to induce the yielding in the steel, the relationship of the strength gain versus the confinement stress, which has the direct proportion to $\rho_{s} f_{y} / 2$, is found almost not to be affected by the strength of concrete. In case of the square sections, the capability of concrete to cause steel yielding depends on the strength of both materials. In general, relatively low strength of concrete will not be able to induce the plasticity in steel and therefore, the confinement efficiency is lower. To increase confinement efficiency, higher strength of concrete should be used, since it will extend the effective range of steel volume where the steel yields (Fig.11, Case 1 and 2).

The relationship between the confined mean stress and the amount of steel can be seen in Fig.12 for different set of material properties. As for circular sections, the relationship concerned remains proportional. For square sections, we can see in Fig.12 (Case 1 and Case 2) that the range of the plastic mode of steel failure expands with the increase of the compressive strength of concrete. The higher strength concrete for the square section functions to induce yielding in the greater deal of steel surrounding concrete.

It can be summarized that the confinement efficiency related to the amount of steel is not affected by the strength of concrete when circular section is assumed, but much influenced by the concrete strength on the strength gain in the case of square confinement. This interaction has not been rationally linked with the design equations to specify the stress-strain relationship of the confined concrete for design purposes.

\section{(2) Yield strength of steel}

For circular sections, the increment of yield strength of steel, as predicted, increases the strength gain proportionally as shown in Case 1 and

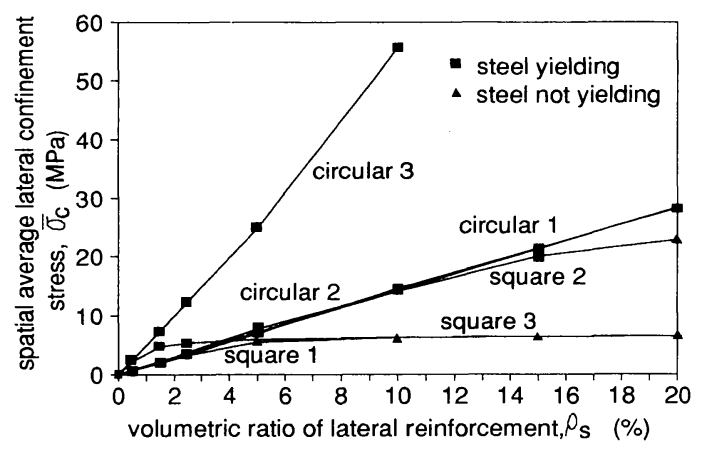

$$
\begin{aligned}
& \text { Case } 1: f_{c}{ }^{\prime}=25 \mathrm{MPa}, f_{y}=240 \mathrm{MPa} \\
& \text { Case } 2: f_{c}{ }^{\prime}=100 \mathrm{MPa}, f_{y}=240 \mathrm{MPa} \\
& \text { Case } 3: f_{c}{ }^{\prime}=25 \mathrm{MPa}, f_{y}=960 \mathrm{MPa}
\end{aligned}
$$

Fig.12 Effect of Material Properties to Confined Mean Stress

Case 3 of Fig.11. It is easily understood that by increasing the yield strength, since the circular section always has capability to induce steel to the plasticity range, the level of confinement provided by steel casing also increases according to Eq.(5).

However, in case of square sections, almost no increment in the strength gain due to the increment of the yield strength for greater amount of steel. In other words, the maximum level of confinement provided by steel casing is the same regardless of the value of yield strength when we place large amount of steel as shown in Fig.12 (Case 1 and Case 3). Because of non-uniformity distribution of stresses and the local damage in the square sections, the capacity of confined concrete to induce yielding in the steel is not affected by the yield strength of steel since ultimate mode is decided by the mode of concrete failure. Only fewer steel and/or higher compressive strength of concrete are needed to reach the most efficient usage of steel in the case that the higher yield strength is employed.

\section{CONCLUSIONS}

The elasto-plastic and fracture constitutive model was installed in $3 \mathrm{D}$ finite element program "COM 3" to serve the analytical investigation on the confinement efficiency by lateral steel to confined concrete. The analytical approach to the inelasticity of confined concrete columns enabled us to manifest the mechanism and to quantify the confinement efficiency associated with the geometry and amount of lateral steel as well as the properties of constituent materials as follows.

(1) It was clarified that the strength gain due to confinement is approximately proportional to the sectional averaging of the lateral mean stress at each particular point in a section, regardless of the geometry of steel arrangement, while the propor- 
tion sensitivity of the strength gain versus the spatially averaged lateral mean stress is dependent on the type of steel laterally placed. The $3 \mathrm{D}$ finite element analysis was verified to quantify the confinement efficiency related to the geometry of lateral steel.

(2) The sectional averaging of the lateral mean stress was found to be exactly proportional to the amount and the yield strength of steel for circular sections. But as for square sections, it was numerically shown that the linearity between the mean confinement stress in concrete and the amount of steel does not hold. It means that the strength gain cannot be rationally predicted by the conventional factor " $\rho_{s} f_{y}$ " where $\rho_{s}$ is the volume ratio and $f_{y}$ is the yield strength of steel.

(3) The confinement effectiveness for square section is not improved when the amount of lateral steel gets large. The nonlinear relation of the strength gain and the volume ratio of steel casing is rooted in the premature failure of concrete before the yielding of lateral steel. It was numerically investigated that the confined concrete with square section will lose the ability to induce the plasticity to the greater deal of lateral steel. Even if the steel would be added to the confinement system, the stress arising in steel simultaneously gets reduced. As a whole, the confinement efficiency is not improved effectively by increasing the volume of steel.

(4) It was verified that the compressive strength of confined concrete and the yield strength of steel affect the relationship between the lateral averaged stress of concrete and the amount of steel. The higher strength of concrete, which can act to induce the greater plasticity to steel, extends the effective range of steel volume where the whole steel yields and the confinement efficiency is the maximum under the given material. The higher yield strength of steel reserves more confinement stress that can be mobilized, as long as the concrete can induce plasticity to steel.

ACKNOWLEDGMENT : The authors appreciate the guidance and advices given by Prof. $\mathrm{H}$. Okamura, the University of Tokyo. The first author is grateful to German Academic Exchange Service (DAAD), Federal Republic of Germany for the scholarship in Asian Institute of Technology (AIT), Thailand. The financial support was granted to the second author by Japan International Cooperation Agency when he served in AIT and by the Japanese Government in line with Grant-inAid for scientific research No.04555114.

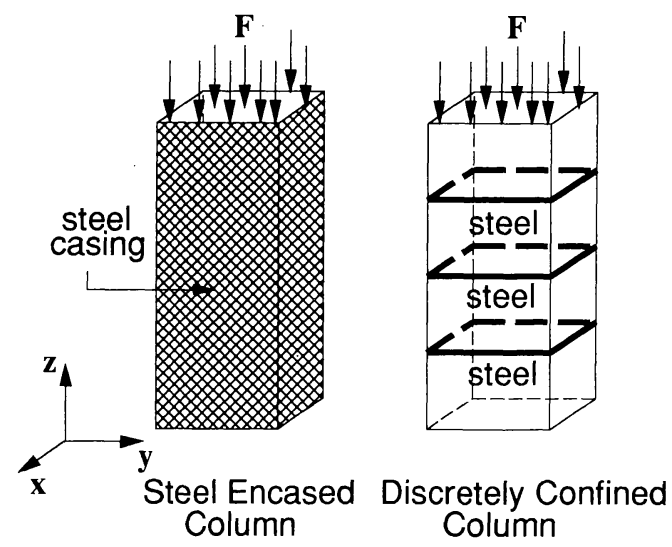

Fig.A 1 Confined Concrete

\section{APPENDIX}

Let us consider the laterally confined concrete as shown in Fig.A 1. Applying the virtual work principle, we get,

$$
\int_{V} \sigma_{i j} \delta \varepsilon_{i j} d V=\int F \delta u d S
$$

where $F$ is the external force applied on the boundary of the domain and $V$ denotes the domain of the whole volume. When we apply the following virtual displacement and associated field of perfect isotropic virtual strain,

$$
\begin{aligned}
& \delta \varepsilon_{x x}=\delta \varepsilon_{y y} \neq 0 \ldots \ldots \\
& \delta \varepsilon_{z z}=0 \ldots \ldots \ldots \ldots \\
& \delta \varepsilon_{i j}=0 \text { for } i \neq j .
\end{aligned}
$$

The right term of Eq.(A-1) becomes zero because $\mathrm{X}$-Y component of $F$ as the surface force applied to the confined concrete is not present.

By substituting the above equations into Eq. (A1) and assuming uniaxial stress state $\sigma_{s}$ in steel, we have the following integrals in the concrete and steel domains, $V_{s^{\prime}}$ and $V_{s^{\prime}}$ as

$$
\begin{array}{r}
\int_{V} \sigma_{i j} \delta \varepsilon_{i j} d V=\int_{V_{c}} \sigma_{c, i j} \delta \varepsilon_{i j} d V+\int_{V_{s}} \sigma_{s, i j} \delta \varepsilon_{i j} d V=0 \\
\cdots \cdots \cdots \cdots \cdots \cdots \cdots \cdots \cdots \cdots \cdots \cdots \cdots \cdots \cdots \cdots \cdots \cdots \cdots \cdots \cdots \cdots \cdots \cdots \cdots \cdots \cdots \cdots \cdots \\
\delta \varepsilon_{x x} \int_{V_{c}}\left(\sigma_{c, x x}+\sigma_{c, y y}\right) d V+\int_{V_{s}} \sigma_{s} \delta \varepsilon_{s} d V=0
\end{array}
$$

According to compatibility condition of the prescribed field, the virtual strain along lateral reinforcement coincides with the value designated by Eq.(A-2) regardless of the way of steel arrangement. Then, we have,

$$
\int_{V_{c}}\left(\sigma_{c, x x}+\sigma_{c, y y}\right) d V+\int_{V_{s}} \sigma_{s} d V=0
$$

Here, let us define the local lateral confinement stress which is the first invariant under two 
dimensional stress field by taking,

$$
\sigma_{c} \equiv \frac{\sigma_{c, x x}+\sigma_{c, y y}}{2} \text {. }
$$

By substituting Eq.(A-6) into Eq.(A-5), we have,

$$
2 \int_{V_{c}} \sigma_{c}(X, Y, Z) d V+\int_{V_{s}} \sigma_{s} d V=0
$$

In using the above equation, we can compute the spatial averaging of the local lateral confinement induced in concrete with respect to the steel stress, as follows;

$$
\begin{aligned}
\bar{\sigma}_{c} & =\frac{1}{V_{c}} \int_{V_{c}} \sigma_{c}(X, Y, Z) d V \\
\bar{\sigma}_{c} & =-\frac{1}{2 V_{c}} \int_{V_{s}} \sigma_{s} d V \cdots \cdots \cdots
\end{aligned}
$$

Provided that the whole domain of the lateral steel would be in yield condition where the steel reaches the yield strength $f_{y}$, the spatial averaging of lateral confinement becomes,

$$
\begin{aligned}
\bar{\sigma}_{c} & =-\frac{1}{2 V_{c}} \int_{V_{s}} f_{y} d V=-\frac{1}{2 V_{c}} f_{y} V_{s}=-\frac{1}{2}\left(\frac{V_{s}}{V_{c}}\right) f_{y} \\
& =-\frac{1}{2} \rho_{s} f_{y} \cdots \cdots \cdots \cdots \cdots \cdots \cdots \cdots \cdots \cdots \cdots \cdots \cdots \cdots \cdots \cdots \cdots \cdots \cdots \cdots \cdots \cdots
\end{aligned}
$$

\section{REFERENCES}

1) Ahmad, S.H., and Shah, S.P. : Complete Triaxial StressStrain Curves for Concrete, Journal of the Structural Division, ASCE, 108 (4), 728-742, 1982.

2) Ahmad, S.H., and Shah, S.P. : Stress-Strain Curves of Concrete Confined by Spiral Reinforcement, American Concrete Institute Journal, 79 (46), 484-490,1982.

3) Burdette, E.G., and Hilsdorf, H.K. : Behavior of Laterally Reinforced Concrete Columns, Journal of the Structural Division, ASCE, 97 (2), 587-602, 1971.

4) Iyengar, K.T.S.R., Desayi, P., and Reddy, K.N. : Stress Strain Characteristics of Concrete Confined in Steel Binders, Magazine of Concrete Research (London), 22 (72), 173-184, 1970.

5) Kent, D.C., and Park, R. : Flexural Members with Confined Concrete, Journal of the Structural Division, ASCE, 97 (7), 1969-1990, 1971.

6) Mander, J.B., Priestley, M.J.N., and Park, R. : Theoretical Stress-Strain Model for Confined Concrete, Journal of the Structural Division, ASCE, 114 (8), 1804-1826, 1988.

7) Maekawa, K., and Okamura, H. : The Deformational Behavior and Constitutive Equations for Concrete Using
Elasto-Plastic and Fracture Model, Journal of the Faculty of Engineering, The University of Tokyo (B), 37 (2), 253328, 1983.

8) Maekawa, K., Takemura, J., Irawan, P., and Irie, M. : Continuum Fracture in Concrete Nonlinearity under Triaxial Confinement, Proceedings of JSCE, 460/V-18, 113-122, 1993.

9) Maekawa, K., Takemura, J., Irawan, P., and Irie, M. : Plasticity in Concrete Nonlinearity under Triaxial Confinement, Proceedings of JSCE, 460/V-18, 123-130, 1993.

10) Maekawa, K., Takemura, J., Irawan, P. and Irie, M. : Triaxial Elasto-Plastic and Fracture Model for Concrete, Proceedings of JSCE, 460/V-18, 131-138, 1993.

11) Okamura, H., and Maekawa, K. : Nonlinear Analysis and Constitutive Models of Reinforced Concrete, Giho-do Syuppan Co. Ltd., Tokyo, Japan, 1991.

12) Okui, Y., Horii, H. and Akiyama, N. : A MicromechanicsBased Continuum Theory for Strain Localization and Softening Under Compression, Fracture Mechanics of Concrete Structures, ed. Bazant, Z.P., 275-280, 1992.

13) Sargin, M. : Stress-Strain Relationships for Concrete and the Analysis of Structural Concrete Sections, Study No.4, Solid Mechanics Division, University of Waterloo, 1971.

14) Sheikh, S.A. : A Comparative Study of Confinement Models, American Concrete Institute Journal, 79 (30), 296306, 1982.

15) Sheikh, S.A. and Uzumeri, S.M. : Strength and Ductility of Tied Concrete Columns, Journal of the Structural Division, ASCE, 106 (5), 1079-1102, 1980.

16) Sheikh, S.A., and Uzumeri, S.M. : Analytical Model for Concrete Confinement in Tied Columns, Journal of the Structural Division, ASCE, 108 (12), 2703-2722, 1982.

17) Soliman, M.T.M. and Yu, C.W. : The Flexural StressStrain Relationship of Concrete Confined by Rectangular Transverse Reinforcement, Magazine of Concrete Research (London), 19 (61), 223-238, 1967.

18) Song, C., and Maekawa, K. : Dynamic Nonlinear Finite Element Analysis of Reinforced Concrete, Journal of the Faculty of Engineering, The University of Tokyo (B), 41 (1), 73-158, 1991.

19) Vallenas, J., Bertero, V.V., and Popov, E.P. : Concrete Confined by Rectangular Hoops and Subjected to Axial Loads, Report No.UCB/EERC-77/13, Earthquake Engineering Research Center, University of California, Berkeley, 1977.

(Received October 16, 1991)

連続鋼材により拘束されるコンクリートの強度・破壊解析

Paulus IRAWAN・前川宏一

連続鋼材により横拘束されるコンクリートの軸圧縮挙動を, 弾塑性破壊構成則を用い た 3 次元有限要素解析により検討した. 円形断面では横補強鋼材は最終的に降伏に至る が, 補強量の大きい正方形断面では, 鋼材の非降伏領域の発生のため, 鋼材量と横拘束 力の関係に強い非線形性が現れる。これは，コンクリートの隅角部，中間部での応力状 態の非均一性と, 相当する破壊と塑性の進行性の差異によって説明された. 